\title{
Fleshing the Interface
}

Dianne Reid

To be a mature dance artist is a particular act of survival. It requires both a hardening of political resolve and a softening into the complex flux of physicality. There is a richness of expression, personal and technical, that lives within the mature dancer's body-textural detail and virtuosic nuance that emerges from the experiential. There are emotions and truths housed in this physicality that dancing can access...

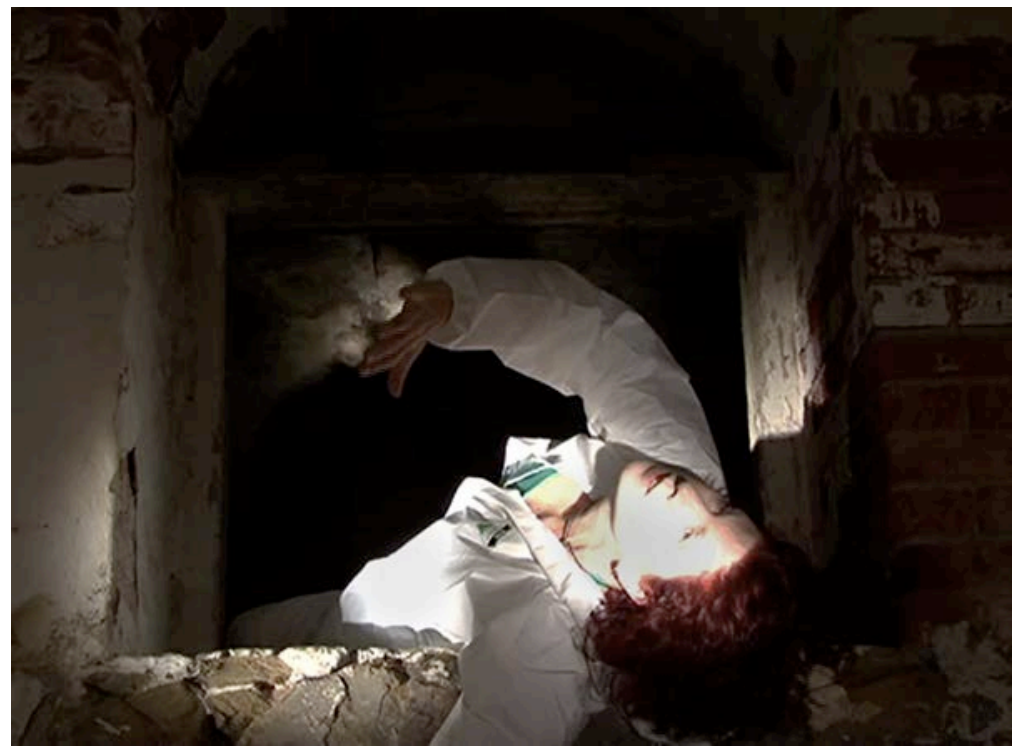

Figure 1:

Dance Interrogations in the Medina Treasury

Tunnels, 2012

Image courtesy of the artist

People talk about "getting their head around something" as a euphemism for understanding, accepting, or mastering an idea. The phrase supports the notion that one must move away from and then back inside an experience to appreciate its complexity and detail, its multiplicity. As artists pick up cameras and begin to look at the moving body from a number of perspectives simultaneously, they began a multifarious journey that connects and complicates the roles and languages of author and subject across spaces, sites, and art forms. Screendance is a complex circumnavigation of flesh and pixels, of dissection and resurrection, unfixing in order to re-render the moving body to the sum of and greater than its parts. To work as a screendance artist is to enter a creative and philosophical loop that begins seeking to capture and fix the dance experience and, in the process, discovers possibilities for undoing, diversifying, and reconfiguring the danced exchange. 
Screendance dismantled my proscenium arch, liberated my body in space and time, and enabled me to dance (and dance for) audiences existing in other spaces and times. The camera provided me with a means to guide my audience more directly into my body - and then to ride my point of view and rhythms as I cut together my dance journey.

In choreographing for video I am exploring mechanisms by which I can translate the kinaesthetic intimacy of dance and the body to the screen-to make my sweat bead on the surface of the screen. In doing so, I am drawing attention to the "individual" experience, the emotional and psychological landscape which "lives" in the physical landscape. ${ }^{2}$

Creating dance for the screen grew from a desire to find a more direct link for the audience to my creative vision, to my imagination. It enabled me to capture a particular moment, an intimacy and, by fixing it (at first on film or videotape, then as digital files), to hold onto and replay that exact moment. It is proof that my dance/my body/l exist - I have a tangible history of experience and emotion and idea, that moves and feels and speaks for and to you, the viewer, and I can share it with you as quickly as your internet connection allows. Some years ago I wrote about my journey from choreographer to dance video artist as an "unlearning of my role and processes as choreographer." ${ }^{3}$ Excited by the choreographic potential of video editing, I identified with Maya Deren's statement that it was like "finally finding the glove that fits... and I could move directly from my imagination onto film."4

I was cutting choreography-re-defining screen narrative through a kinaesthetic script and re-defining the spatial and temporal constructions of my choreography through the cinematic tools of montage. ${ }^{5}$

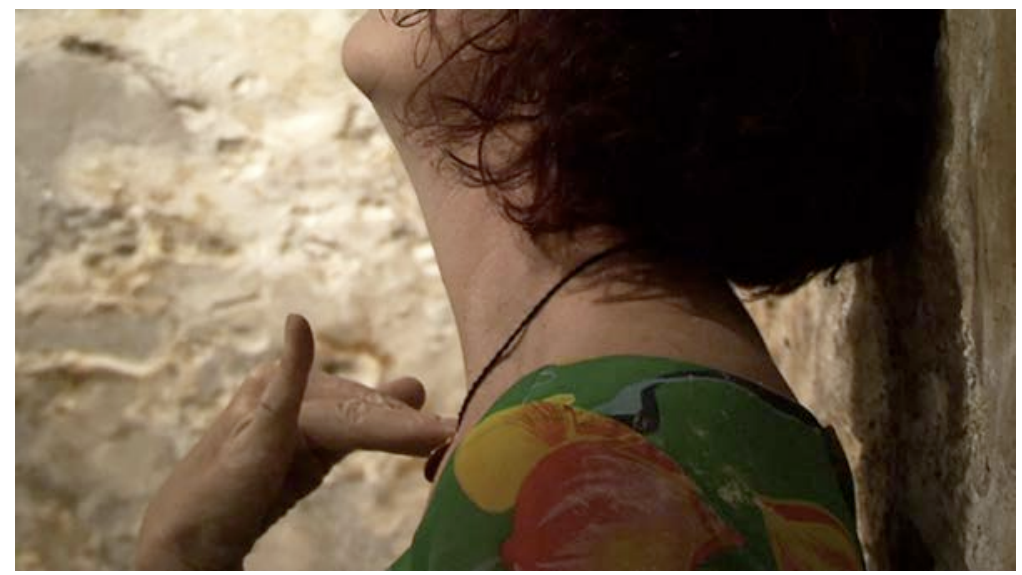

Figure 2:

Image from Dance Interrogations Promotional Video

Courtesy of the artist 
Over the last ten years (and the first decade of this new millennium), a period that frames the creation of my body of screendance work, the physical body has become more distant in a cultural sense. Our lives operate over multiple sites-we are "interfaced" rather than face-to-face, and we must search for our three-dimensionality inside the pixels and portals of technology. A body in a physical landscape is re-sited as it is technologically captured to the frame of the screen or to the motion capture software, then "recorporealized to another storage medium such as tape or DVD. Finally, it is re-sited again at its end point, as a screen image." 6 That which sought to bring us closer has separated us. We become veiled through these tiers of representation, seeing and seen through the eye of the lens not the lens of our eye. This shift in our cultural way of looking and being in the world has affected how we view and make screendances (that term itself an evolution through the many stages of development of the field). ${ }^{7}$ The tools of recording and manipulating an image are at every consumer's fingertips. The mobile phone condition has reached epidemic proportions, hunching us, thumbs a-quiver, over the tiny screens in the palms of our hands. Thousands of domestic production houses walk the streets capturing, colouring, cutting and copying their own and every footfall. The collaborative, creative artwork has been squashed underfoot by this unseeing image-eating machine-a guerrilla audience bent on the upgrade, reducing "reflection" to replication rather than rumination.

In a culture like ours, so preoccupied with images of bodies and bodies of images, we tend to forget that both our bodies and our vision have lived dimensions that are not reducible to the merely visible. ${ }^{8}$

As much as I celebrate the possibilities of a new piece of technology, I have been mourning the physical body. As I upload my screendances to YouTube and Vimeo, as I submit them to a festival on the other side of the world, I begin to feel like the proverbial tree falling in the forest-invisible and intangible again. Even though I can count the number of "views," these are disembodied viewers. The online and "televisualized"9 connection doesn't have the quality of the fleshy interface; we cannot touch. I miss bumping into people. I yearn for the risk of the live collision, the happy accident, the fleeting encounter, the spontaneous revelation, the connection of body to body. I want to now undo the screendance artefact and re-configure it into a live encounter, a process "unplugged."

And, over the past decade, another thing has happened and is happening with my relationship to dance and choreography-that relationship has matured. Of course, my physical body has matured and this is gradually shifting my range and stamina, but rather than being a loss, it is a redirection. In fact, it is a refinement. It is recognition of the wealth of creative material that now resides in my body, which can be accessed through improvisation. This extends beyond dance "steps" to the many aspects of my lived experience, both real and imagined. I am carrying hours and hours of footage, which, with performance practice, can be edited in real time in the presence of the audience, placing the lens in our collaborative hands. 
Interestingly I find that my question remains the same throughout my journey as a screendance artist:

If I can direct the viewer through the verbal and language, to the kinaesthetic, and if I can merge form and content more directly, can I lead the viewer to a physical utterance? My task ... became a desire for this convergence-a direct relationship between form and content, between spectator and performer/author, between the language exterior and the felt interior. ${ }^{10}$

And so now I have begun a particular dance interrogation, a probing of the many screendance sites, simultaneously, finding and crafting frames of and on the body in the same space and time in duet with my audience. I am proposing a "living screendance" - an interactive art in which the sharing of physical space also shares the power, responsibility, and creative voice. By dissolving the space between performer and audience, invading their intimate and interior spaces through proximity, touch, question, and implication, I seek to interrogate the way we view the dancing body and implicate our bodies as creative and communicative vessels. My role as improvisational performer is simultaneously that of subject and witness, uncovering the artifacts of my experience as I share a particular experience with an audience. I interrogate my physicality and in doing so uncover the traces of emotion, vocabulary, incident, and idea that have moved through my architecture. I implicate my audience in the narrative as our bodies share thirty minutes in a particular architecture. It is a three-dimensional sharing of interior spaces both physical and metaphoric.

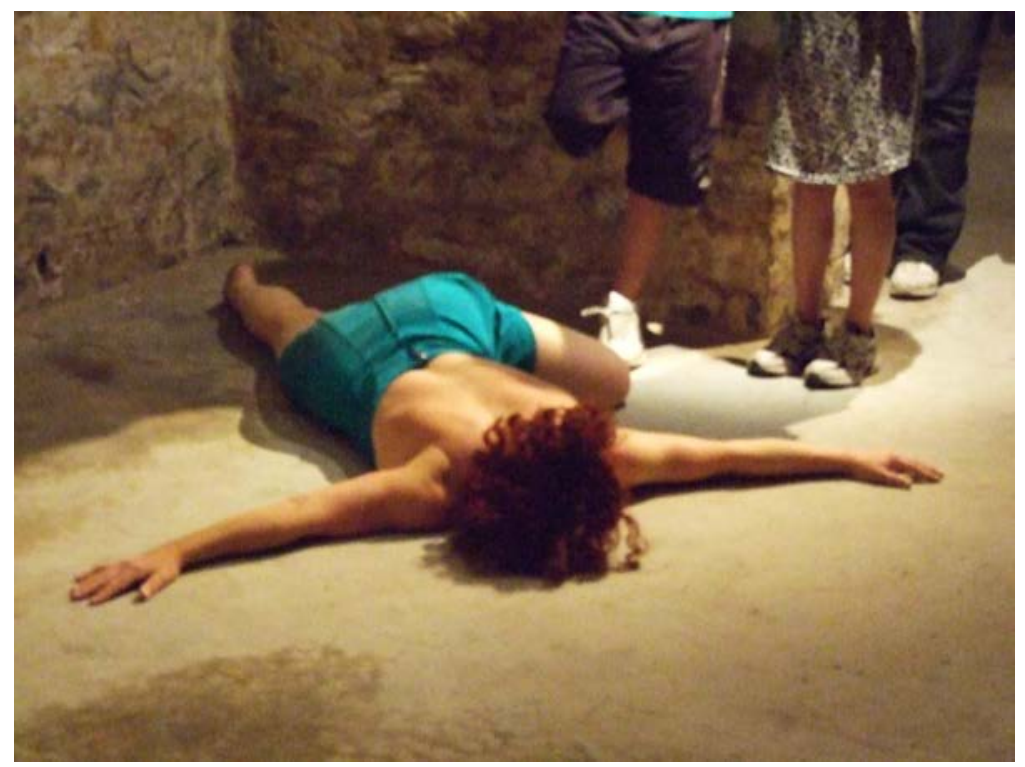

Figure 3:

Dance Interrogations in the Medina Treasury Tunnels (2012)

Photo: Evie Photakis 
Dance Interrogations is the title of an ongoing solo performance practice initiated in late 2011. The title is the clue to the content and the form. Dance is both the location and the tool of interrogation. The questions and responses are about the dance, the body, and the self. But I am a moving target, a shifting site, an aging body, colliding in new ways with other bodies, sites, memories, and images.

Presented in intimate, non-theatrical locations, the thirty minute dance and video "event" is a sharing of space, suggestions and sensations between my actual and imagined bodies ${ }^{11}$ and the bodies of the audience. The role of "audience" is challenged through my movement around, proximity to and interaction with specific individuals, who are also having to stand and move with me and each other in order to: see me as I am hidden by a wall or another body; avoid impact with my dancing body; or in response to my direct suggestion (and because of a limited or complete absence of seating). These viewers are made aware of their own and each other's bodies, themselves providing physical frames and narrative content. Each performance becomes a creative collaboration imposed by the sharing of this site. There is no scripted or pre-choreographed content; the movement and narratives arise out of the moment and the context, albeit with recurring themes about the body/architecture, memory/desire and touch/relationships.

I establish a "frame" for each performance event with the physical site-an interior akin to an interrogation room or holding cell, one that might serve as a metaphor for the body's interior. For the Adelaide Fringe 2012, the site was a tunnel in the basement of what was once the Treasury Building, a trio of small vaults of distressed sandstone and brick. The crumbling textures and the window and door openings leading to another hidden tunnel provided metaphoric material for the body, aging, memory, inscription-the architecture implying the body's interior, the lungs and stomach, or the circulatory system.

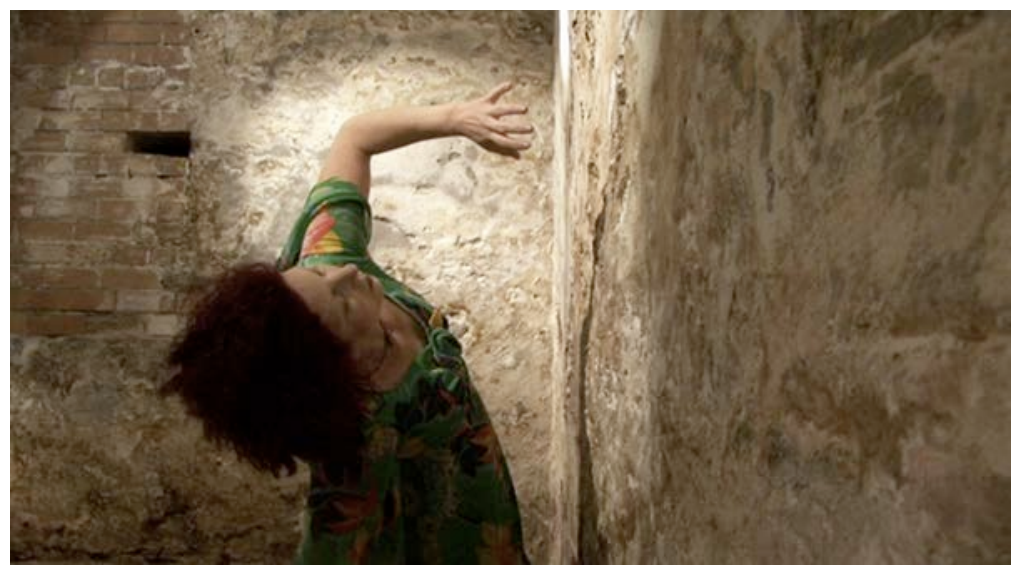

Figure 4:

Image from Dance Interrogations Promotional Video

Courtesy of the artist 
A subterranean space, a crypt, dungeon, a derelict tunnel-with a door and a window leading to a closed narrow space of soil ... Like a body, the caverns of the internal torso resolving into the matter of the layers of fascia. My audience and I were inside a larger body ... vaulted spaces like lungs lined with a crumbling brick and stone vault of rich reds and creams, flaking and fluted, that came away in my hands, stained my feet, scratched and bruised my limbs. We were all foreign bodies in this architecture and my forensic examination extended from stone to flesh, across and around the negative spaces of their bodies, climbing them and their reactions as I physically scaled the walls, ledges...

Disappearing from view behind other bodies or the wall masking another cavity ... using their windows and doorways to privilege a gesture, to illuminate a detail, illustrate a connection. Their moving flesh providing pathways and places to rest ... my shifting of levels and relationships to gravity building perspectives on their landscapes, changing their scale and balance. I lie between someone's feet and look up-they become my Everest and I become their fallen body. I fit myself into their curves and edges-solve the jigsaw of that performance's population as I find their elbow point fits into the cup of my hand, my ear onto the top of their shoulder, a side of a head resting into the hip crease. I approach as a familiar friend, a like-mind, and they allow me to build our relationship of similarity, support, and comfort. Their physicality is written into the narrative. They are co-authors and co-actors, kin, a community brought together by the consequence of site. ${ }^{12}$

My venue for the Edinburgh Fringe was a blacked-out, two meter square hotel room. With the walls invisible and only a small circle of light on the carpeted floor, it was as if the audience and I were suspended in a muffled womb.

The solo in Edinburgh became a true interrogation a black hole of an interview room with space for only a handful of victims I began the season with it empty except for my body, sometimes laying mid-floor, sometimes blurring the edges and as the days progressed, added or subtracted chairs, static forms-4 grouped for a card game or 1 laying askew as though a scuffle has occurred-the interactions with audience became much more loaded and intense framed in this darkness (than the tunnel in Adelaide)

and yet still some trust developed over the 30 minutes so these strangers became collaborators in my unpacking...

bits of joy jumping us in unison, pieces of longing connecting our hands and cheeks the added final image of my ghostly self on my stripped back body helped spear the black, pierce an opening in our minds to another time, location, identity beyond that show's hundred moments ${ }^{13}$ 
I incorporated two discrete moments of video projection onto the surface of my own body, drawn from an earlier solo work, literally referencing a past or lost self. I became the screen, my body the site of the screendance via my "skins," the micro landscapes of costume layers that are populated by video projected imagery and animated as they are revealed or discarded. I wanted to be able to peel myself, to metaphorically get under the surface, to reveal other identities, past selves, dreams, traumas. At about halfway through the work I reveal an opening in the room and, through a beam of projected light, let in another world. Past selves alluded to up until that point now appear as moving images. My real body is stopped, as are my audience who must herd into a small group parted by the beam of light in order to see the projected imagery. We are all pinned by this new artificial interface as I am speared by micro images of myself crawling and climbing over my torso. I am zooming in on myself-amplifying a moment edited into a new multi-layered exchange, my screen self interacting with the frame of my live body in direct physical relation to my viewers. It is both ridiculous and reflective, this metaphor for technology's "breaking" of the body; we are reduced and reproduced, defying gravity and yet still falling.
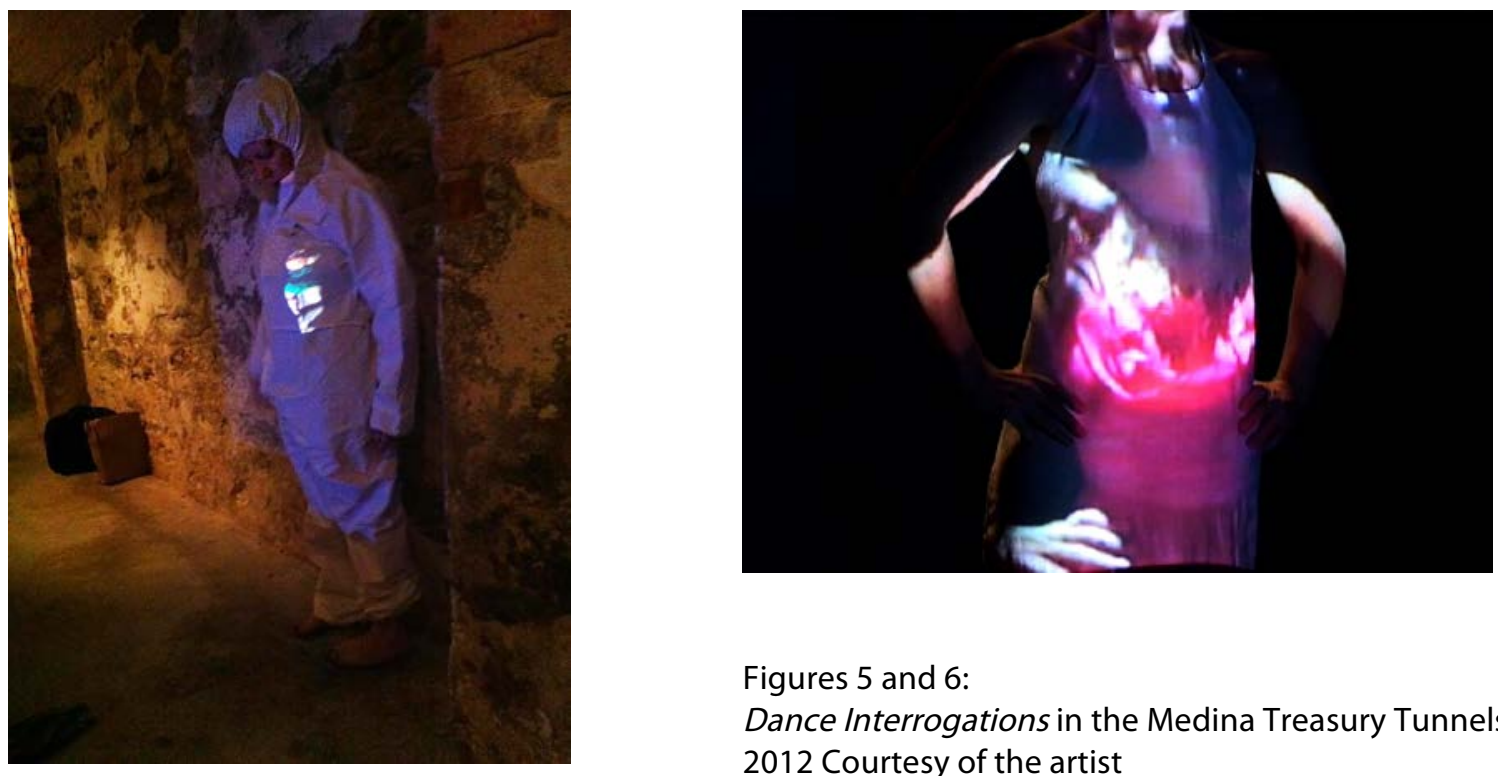

Figures 5 and 6:

Dance Interrogations in the Medina Treasury Tunnels 2012 Courtesy of the artist

As she runs up against more walls, scrapes along more floors, the suit becomes worn and ripped. Eventually its use has been served and it is removed, revealing the floral dress underneath... and the tone of the piece changes a little. With skin shed, everything seems a little bit more accessible now; there's not as much need in the movements. Reid still performs in the audience's face, but rather than feeling confronting, it almost feels a little... well, joyous. ${ }^{14}$ 
Joy: that feeling eludes us in our post 9/11 terror-ridden existences. We need to reconnect with that possibility in our bodies, the possibility of opening, releasing, engaging, listening, laughing, and noticing. When I improvise, my dance magnifies ordinary moments and celebrates the present moment. In this way its historical and social background is that of the viewer, rather than of the dance itself. It brings together fragments of many people, places, and ideas into a dense and diverse summary.

"... through improvisation I was going to be able to live ... therefore I see it as a life practice, so that what I'm working with when I'm improvising is not separate from how I'm looking at living and how I'm looking at my relationships ... it has to do with our place on the planet here and what we're doing ... I think a lot of people are looking for something else now because things are getting so bad ... people are going 'wait a minute! What do we need for life to have more meaning?"115

Susan Kozel talks about "distributed intelligence," how "our thinking, our moving through the world, occurs on a full body level." ${ }^{16}$ The attentive state of improvisation stimulates and illustrates an integration of the cognitive and the physical. There is potential to access knowledge through moving. To work in dance is always to be working in relationship with moving and changing bodies. We are all being re-made day to day, physically and emotionally, and so the need to attend to the "now" is paramount. Improvisational scores are exercises in live, "fleshed" editing.

As an improviser, with or without camera, I am engaging in the present moment, paying attention - to my breath, to the moment when breath becomes sound, to what a movement uncovers, to sensation, to what distracts me. Now ... I am noticing the juxtaposition ... of my body and the buildings I move through. I am considering the potential of my breath to permeate their surfaces and for their particles to move through me. I am enjoying the idea that structures can be fluid and that the poetic intersects with the academic. ${ }^{17}$

In my live screendance I perform and edit simultaneously. I craft in the moment using my body and imagination as a changing landscape upon which other temporal scenes and identities are played out in relationship to those viewing. I perform within and in direct contact with the audience and our shared physical site. The nontheatrical and/or small spaces I use force the audience to move to view or to view from different angles and proximity (or at least to be made aware of these choices). By using screendance projections onto my live body (and, in the future, hopefully also onto the bodies of those in the audience) I stretch the physical site into more dimensions, using projected footage to see the interior, the desired, the imagined, the fears, regrets, the anatomical workings.

And so we come back around again, in this circumnavigation of the screendance-reconfiguring our relationships to the dancing body, the living body, 
one another. The question of the elusive body keeps turning up, and with it, the question of sustainability. My dancing body is a war memorial, a reminder that all our clever complications begin and will end in this fleshy interface.

Maggi Phillips, in her paper "Diversified moves of a specialised ecology: can this art form be sustainable," ${ }^{18}$ suggests that "our greatest strengths derive from our imaginative capacity" and that we could "approach the complex problem of sustainability of the art form ecology with an unpredictable play of ideas." The future of the dance form, our capacity to connect to our embodied knowledge, "[begins] with the small moves in imaginative play, extending outwards to connect with other human beings, other spheres, other perspectives."

The reflective abilities cultivated by artists can offer new perspectives and procedures to attempts to naturalize phenomenology and forge a first-person science ... turning reflective movement into heuristic tools. $^{19}$

Coming close to other bodies, either via the camera or in the intimate live encounter, is revolutionary. It dismantles the status quo. It is a particular feedback that enables me to sustain a dance practice and to consider its capacity to enhance our interrelationships with each other and our bodies/selves. It reminds us that we are made of the same matter.

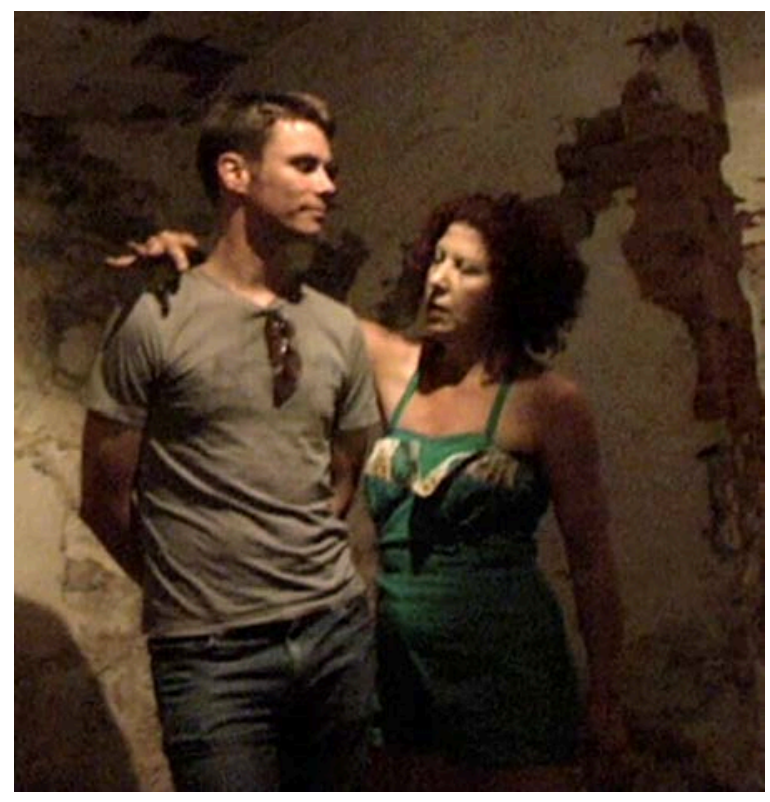

Figure 7:

Dance Interrogations in the Medina Treasury Tunnels 2012

Courtesy of the artist

Matter is not mortal ... it is transformational, it moves through time and space, from form to form, but it is never lost. We know about this kind of immortality; our intimations of it take a million bodily forms-the curve of the child's head inherited from his great-grandfather, the familiar posture of a woman sweeping, passed down since time immemorial, 
the hand raised in farewell, the curve of the lips smiling a greeting; these are the genetic and social ways we humans endure forever. But the transformation of our personal matter extends beyond the genetic and social world of humans; the material each one of us is made from comes from and goes to the world around us. ${ }^{20}$

There is something about the feedback and interaction of the real-time dance encounter that I ultimately want to capture as a screen work, perhaps in some relationship to the live act (the format of that will reveal itself as I go). There's this wonderful irony in the evolution of my screendance practice-seeking to make dance tangible by transposing the real body onto a virtual skin, then seeking to make it more elusive, unique, by dropping it back into the clunkiness of the biological structure. And now, I seek to shift the perceptions of the dancing body again-dismantling and reforming digital architectures within the physical body, giving weight to the transient, significance to the incidental-considering the global impact of a single event. A "recorporealization ... the complete construction of an impossible cinematic body, in which the real and the fictive are hybridized."21

I'm writing about the video projections and thinking about the dilemma of wanting to be unrehearsed/unplanned but also to have access to ready-made images at any time and place during the event. Like with improvisation I can assign certain moods or events to particular parts of

the space ... possibilities of hot spots that animate myself or the audience (I think I do only want imagery to fall onto skin ... real skin, or the worn or discarded skins of clothing) ... To what extent do I want to pre-write material and assert control over (parts of) the event? Or amplify the unknowns? I think I just want to keep shifting around the problem, the problem of me and you ... a variety of documents of the process, to create other collages...setting up different configurations of spaces, material, people, cameras... and I think about improvisation as a long-term practice, how to access the peculiarities of the now (today's body is different to yesterday's), to stay fresh in the recurring images, acknowledging my habits but unpacking it anew for someone else... Virtue/osity ... today's undoing... ${ }^{22}$ 


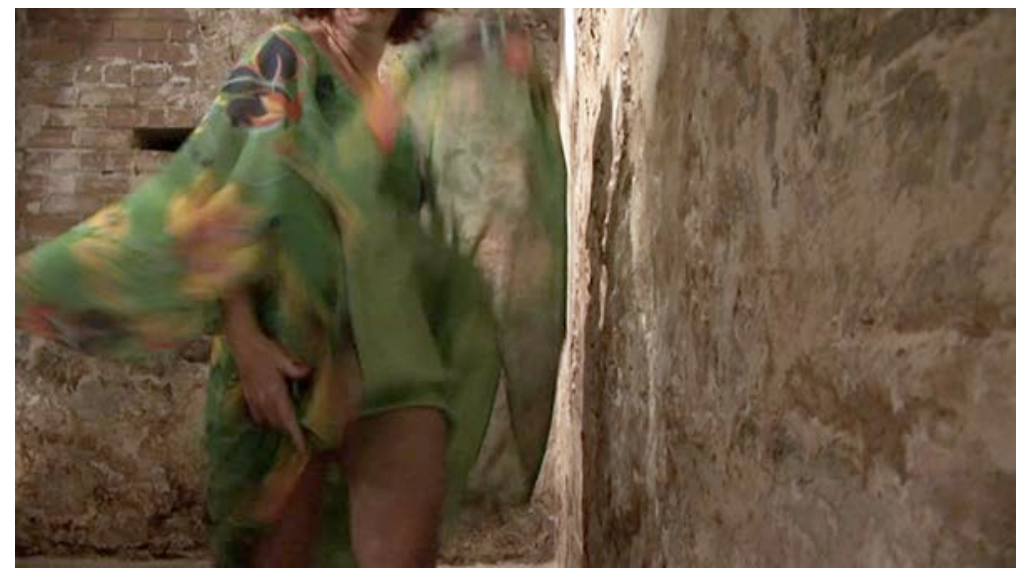

Figure 8:

Image from Dance Interrogations

Promotional Video

Courtesy of the artist

\section{Notes}

1. Dianne Reid, "dance as an act of survival," May 2, 2012, http://hipsync.blogspot.com.au/.

2. Dianne Reid, "Cutting Choreography," in Practice as Research: Approaches to Creative Arts Enquiry, eds. Estelle Barrett and Barbara Bolt (London and NY: I.B.Tauris \& Co. Ltd, 2007), 47.

3. Ibid.

4. Maya Deren, "Biographical Statement," in The legend of Maya Deren: a documentary biography and collected works, eds. V. A. Clark et al. (New York: Anthology Film Archives/Film culture, 1984), 57. In the foreword to this volume, the authors state that all the documents written by Maya Deren came from the Maya Deren Collection of the Boston University Library, and the libraries at UCLA, UC-Berkeley, Cornell, and Syracuse.

5. Reid, "Cutting Choreography," 55.

6. Douglas Rosenberg, Screendance: Inscribing the Ephemeral Image (New York: Oxford University Press, 2012), 17.

7. "Screendance...though not a perfect term, implies that the method of apprehension (the screen) modifies the activity it inscribes (the dance); in doing so it codifies a particular space of representation and, by extension, meaning. Those other terms - video dance, filmdance, dance for camera, and so forth-should instead be considered as specific subcategories of screendance." Ibid., 3. 
8. Vivian Sobchack, "Is Anybody Home? Embodied Imagination and Visible Evictions," in Carnal Thoughts: Embodiment and Moving Image Culture (Berkeley: University of California Press, 2004), 179.

9. "Televisualized" is a term coined by Sherril Dodds in her article of the same name.

10. Reid, "Cutting Choreography," 56-57.

11. I perform "imagined" bodies through projected video imagery, or a discarded costume, or via spoken word description.

12. Dianne Reid, PhD Journal entry, January 8, 2013.

13. Dianne Reid, "International Reflections," September 16, 2012, http://hipsync.blogspot.com.au/2012/09/international-reflections.html.

14. Pete Muller, "Dance Interrogations," Festival Freak, December 16, 2012, accessed January 1, 2013 http://ff.moobaa.com/?p=3307, emphasis added.

15. Kirstie Simson, qtd. in Force of Nature, dir. Katrina McPherson (Scotland: Goat Media, 2011).

16. Susan Kozel, "Connective Tissue: The Flesh of the Network," paper presented at Dance rebooted: initializing the grid (Deakin University, Melbourne, Australia:

Ausdance, 2004).

17. Reid, "Making things visible," 89.

18. Maggi Phillips, "Diversified Moves of a Specialised Ecology: Can This Art Form Be Sustainable?," paper presented at Dance rebooted: initializing the grid (Deakin University, Melbourne, Australia: Ausdance, 2004).

19. Jondi Keane, "Embodied Cognition Is a Special Type of Movement," paper presented at Dance dialogues: conversations across cultures, artforms and practices (Melbourne, Australia, 2008).

20. David Suzuki and Amanda McConnell, The Sacred Balance: Rediscovering Our Place in Nature (St. Leonards, NSW: Allen \& Unwin, 1997), 197.

21. Rosenberg, Screendance, 49-50.

22 Reid, PhD Journal entry, January 21, 2013.

\section{References}

Clark, VèVè A. The Legend of Maya Deren: A Documentary Biography and Collected Works. New York: Anthology Film Archives/Film Culture, 1984. 
Clark, V. A. et al., eds. The legend of Maya Deren: a documentary biography and collected works. New York: Anthology Film Archives/Film culture, 1984.

Dodds, Sherril. "Televisualised." Dance Theatre Journal 13, no. 4 (1997): 44-47.

Keane, Jondi. "Embodied Cognition Is a Special Type of Movement." Paper presented at Dance dialogues: conversations across cultures, artforms and practices. Melbourne, Australia, 2008.

Kozel, Susan. "Connective Tissue: The Flesh of the Network." Paper presented at Dance rebooted: initializing the grid. Deakin University, Melbourne, Australia: Ausdance, 2004.

Muller, Pete. "Dance Interrogations." In Festival Freak. Adelaide, South Australia, 2012. Accessed January 1, 2013, http://ff.moobaa.com/?p=3307.

Phillips, Maggi. "Diversified Moves of a Specialised Ecology: Can This Art Form Be Sustainable?" Paper presented at Dance rebooted: initializing the grid. Deakin University, Melbourne, Australia: Ausdance, 2004.

Reid, Dianne. "Cutting Choreography." In Practice as Research: Approaches to Creative Arts Enquiry, edited by Estelle Barrett and Barbara Bolt, 47-63. London and NY:

I.B.Tauris \& Co. Ltd, 2007.

---. "Dance Interrogations." http://hipsync.blogspot.com.au/.

---. "International Reflections." September 16, 2012.

http://hipsync.blogspot.com.au/2012/09/international-reflections.html.

---. "Making Things Visible." The International Journal of Screendance 2 (2012): 89-92.

---. PhD Journal, 2013.

Rosenberg, Douglas. Screendance: Inscribing the Ephemeral Image. New York: Oxford University Press, 2012.

Sobchack, Vivian. "Is Anybody Home? Embodied Imagination and Visible Evictions." In Carnal Thoughts: Embodiment and Moving Image Culture, 179-204. Berkeley: University of California Press, 2004.

Suzuki, David and Amanda McConnell. The Sacred Balance: Rediscovering Our Place in Nature. St. Leonards, NSW: Allen \& Unwin, 1997.

\section{Media}

Force of Nature (2011). Dir. Katrina McPherson. Scotland: Goat Media. 75 mins. 